\title{
Product Description/Appearance
}

National Cancer Institute

\section{Source}

National Cancer Institute. Product Description/Appearance. NCI Thesaurus. Code C138990.

Tests using visual inspection to assess the physical state and color of the drug substance or product. 